\title{
LA GERENCIA ACLARADA EN EL TRABAJO DEL ENFERMERO
}

\author{
Isabel Amélia Costa Mendes ${ }^{1}$ \\ Maria Auxiliadora Trevizan ${ }^{1}$ \\ Maria Regina Lourenço ${ }^{2}$
}

Mendes IAC, Trevizan MA, Lourenço MR. La gerencia aclarada en el trabajo del enfermero. Rev Latino-am Enfermagem 2002 setembro-outubro; 10(5):704-8.

La gerencia aclarada presupone que todo individuo de prioridad a una conducta fuerte y determinada, en detrimento de una conducta pasiva. Presupone también una profunda preocupación con las cuestiones de la especie humana, los problemas éticos, la relación con la naturaleza, en fin, con el futuro del hombre. De esta forma, las autoras, basadas en los presupuestos subyacentes a la política de gerencia aclarada de Maslow(1), tienen el objetivo de centralizar este tipo de gerencia en el trabajo del enfermero. Creen que, a través de ésta reflexión los enfermeros podrán incorporar en su práctica nuevos valores, más sintonizados con la naturaleza humana.

DESCRIPTORES: enfermería, gerencia, liderazgo, ética de enfermagem

\section{INFORMED MANAGEMENT IN NURSING WORK}

Informed management presupposes that all individuals will prioritize a taming and determined conduct in detriment of a passive one. It also presupposes deep concern about issues related to the human species, ethical problems, the relationship with nature and, finally, about men's future. In this way, the authors, based on the assumptions underlying the Policies of Informed Management proposed by Maslow, aim at focusing on this type of management in nurses' work. They believe that, by means of such reflection, nurses will be able to incorporate new values which are more harmonized with human nature.

DESCRIPTORS: nursing, management, organization, leadership, ethics, value

\section{A GERÊNCIA ESCLARECIDA NO TRABALHO DO ENFERMEIRO}

A gerência esclarecida pressupõe que todo indivíduo priorize uma conduta desbravadora e determinada, em detrimento de uma conduta passiva. Pressupõe também profunda preocupação com as questões da espécie humana, os problemas éticos, o relacionamento com a natureza, enfim, com o futuro do homem. Desta forma as autoras, fundamentadas nos pressupostos subjacentes à Política de Gerenciamento Esclarecido, de Maslow ${ }^{(1)}$, têm o objetivo de focalizar este tipo de gerência no trabalho do enfermeiro. Acreditam que através desta reflexão os enfermeiros poderão incorporar em sua prática novos valores, mais sintonizados com a natureza humana.

DESCRITORES: enfermagem, gerência, organização, liderança, ética, valor

\footnotetext{
${ }^{1}$ Profesor Titular de la Escuela de Enfermería de Ribeirão Preto de la Universidad de São Paulo, Centro Colaborador da OMS para el desarrollo de la investigación en enfermería, Investigadora 1A CNPq, dirección electrónica (e-mail): iamendes@eerp.usp.br; ${ }^{2}$ Enfermera-Gerente de la Santa Casa de Misericordia de São José do Rio Preto, doctoranda do Programa de pósgrado en Enfermería Fundamental, Escuela de Enfermería de Ribeirão Preto de la Universidad de São Paulo-Brasil
} 


\section{INTRODUÇÃO}

Al tratar del amor y de su desintegración en la sociedad occidental contemporánea, Fromm ${ }^{(2)}$ se reporta al problema humano derivado del capitalismo moderno afirmando que éste régimen social necesita de hombres que presten su cooperación sin rebeldía; hombres que al servirse largamente del consumo, sus deseos de adquisición sean estandarizados y fácilmente previstos; hombres que se sientan libres sin someterse a cualquier principio o consciencia, pero que quieran ser comandados y se presten a hacer lo que de ellos se espera, alineándose en el sistema sin desperdicios; en fin, necesita hombres que sean conducidos sin líderes, impulsados sin objetivo claro, a no ser el de atender expectativas y hacer lo que les es ordenado y exigido.

Como consecuencia del cumplimiento de esas necesidades determinadas por el capitalismo, el hombre moderno "fue transformado en una mercancía, experimentas sus fuerzas vitales como una inversión que precisa proporcionarle el mayor lucro capaz de ser obtenido en las condiciones existentes del mercado". Sus relaciones se caracterizan por el automatismo y su falsa seguridad se fundamenta en el grupo, es decir, "en quedarse junto al rebaño y no ser diferente de él en pensamiento, sentimientos y actos", lo que contribuye para que prosiga alejado de sus aspiraciones humanas más significativas y fundamentales, del deseo de trascendencia y unidad $^{(2)}$.

De ésta forma, el capitalismo arraigado en la cultura organizacional de la sociedad moderna cultivó el espíritu de pasividad y sobrevivencia en el trabajador, comprometiendo el desarrollo de su potencial.

Felizmente, en el mundo de hoy, de cambios constantes y significativos que atraviesan las sociedades, comprender que el potencial humano representa la fuerza esencial de la ventaja competitiva, ha sido valorizado en las organizaciones que buscan la excelencia.

El panorama evolutivo de las transformaciones contemporáneas experimentadas por las sociedades ha indicado que el significado de esas organizaciones está siendo modificado. Sabemos que la intención y la determinación de las organizaciones convergen para la excelencia de su comportamiento en el mercado, es decir, centralizan la obtención de la eficacia en el ambiente externo, en la búsqueda para producir el efecto por ellas deseado.

Al mismo tiempo, las organizaciones están comprendiendo que la expresión de status en estos tiempos difíciles no es una extensa riqueza y sí una justa reputación por los beneficios dados a la comunidad. La formación de una comunidad saludable y acogedora tiene origen en la constitución de un trabajo humano fortalecedor, con alto compromiso de las personas en las decisiones que les competen, ofreciendo constantes oportunidades para aprender y enseñar ${ }^{(3)}$.

El analisis sobre el desarrollo de la comunidad en el lugar de trabajo, demuestra que el principio que define la comunidad es la generosidad ${ }^{(4)}$. Según este autor, "en la era de la información, la mayor necesidad de patrones fluidos de cooperación y la rápida difusión del conocimiento están trayendo la comunidad y la economía de donación de vuelta al primer plano, tanto en el lugar de trabajo como en la sociedad más amplia"(4). Afirma también que un fuerte espíritu comunitario e fundamental para la fidelidad en el ambiente organizacional y que en nuestros tiempos la constitución de una comunidad es una habilidad indispensable y fundamental de liderazgo.

Siendo así, cada vez mas y sobre todo, la organización se ha caracterizado por su dimensión social - su capital humano; las personas constituyen su más preciado patrimonio. Por lo tanto, su proyecto y su responsabilidad más sagrados deben tener en su eje: "tornar eficaces los puntos fuertes de las personas e irrelevantes sus debilidades"(5).

En la época turbulenta en que vivimos, para que una organización alcance las metas establecidas y obtenga el status deseado, se vuelve necesario que ella se realice, con éxito, como comunidad. El cambio es arduo y exige nuevas posturas y nuevos valores, principalmente en lo que afecta al gerenciamiento y al liderazgo.

Creemos que la gerencia aclarada de Maslow ${ }^{(1)}$ pueda ofrecer una importante contribución en ese sentido. De ésta forma, las autoras basadas en sus presupuestos, tienen como objetivo, enfocar este tipo de gerencia en el trabajo del enfermero, pues entienden que a través de esa reflexión ese profesional podrá considerar grata la incorporación de nuevos valores, más sintonizados con la naturaleza humana, en su práctica.

\section{PRESUPUESTOS DE LA GERENCIA ACLARADA}

La gerencia aclarada, propuesta por Maslow ${ }^{(1)}$, parte del principio de que las personas seleccionadas para 
actuar profesionalmente sean suficientemente saludables e decentes, por lo tanto confiables, lo que en tesis presupone circunstancias ambientales y condiciones organizacionales saludables. Siendo así, supone que el individuo de prioridad a una conducta agresiva y determinada asumiendo responsabilidades, en detrimento de una conducta dependiente y pasiva; Que las personas saludables tienen el impulso vigoroso de conseguir, de tornar las cosas mejores y desean realizar con eficiencia y en el tiempo previsto un buen trabajo, considerando las cuestiones estéticas en ese proceso; que existe en el individuo aptitud para ser objetivo e imparcial no solamente en relación con el desempeño de las personas, sino también en lo que le afecta a sí mismo; que las personas son fuertes y tienen capacidad de soportar con firmeza los desafíos y las exigencias, desean que sus necesidades de estima y autoestima sean acogidas y así no queden estacionadas en el nivel de las necesidades de seguridad, pues hay una propensión, una disposición activa, del hombre a la creación y la autorealización.

La gerencia aclarada también presupone el ansia de la persona por ser considerada en su integridad y capacidad de auto-decisión; presume la opción del individuo por el trabajo en vez de la ociosidad, pero argumenta que los hombres dan prioridad al trabajo con significado; que la persona aprecia ver sus realizaciones valorizadas de forma justa y sincera, suponiendo que su crecimiento ocurre a través del placer y también del tedio.

En relación con el sentimiento de las personas hacia el gerente, Maslow ${ }^{(1)}$ cree que los colaboradores desean respetar y amar su gerente; aun así, el respeto es el sentimiento preponderante en relación con el amor. Es decir, entre el respeto y el amor, las personas prefieren respetarlo y no amarlo en vez de amarlo y no respetarlo; sentir miedo no es apreciado por los colaboradores; Aun así, ellos prefieren temerle al gerente antes que despreciarlo.

Los presupuestos de la gerencia aclarada integran también la buena voluntad y la sinergia entre los miembros de la comunidad organizacional, en detrimento de rivalidad y celos. El autor ${ }^{(1)}$ enfatiza que la madurez personal es necesaria en la superación de la rivalidad y de los celos en cualquier equipo. Considera la expresión de hostilidad como reactiva y no fundamentada en carácter. De ésta forma, la libertad de exprimir abiertamente hostilidad, vinculada a determinados motivos o razones, propiciará el incremento de la honestidad; así, ese mecanismo no debe ser reprimido o desanimado.

Los hombres tienen necesidad instintiva de experimentar valores de bondad, belleza, verdad y justicia; por lo tanto, deben ejercitar la vivencia de esos factores ${ }^{(1)}$. De manera general, "las personas sentirán más placer a partir del amor que del odio (aunque los placeres de odiar sean reales y no puedan ser subestimados)". Alerta sobre la dialéctica defensa-crecimiento en relación con las tendencias positivas del hombre, lo que significa que para una buena tendencia hay una contra-tendencia. Siendo así, los seres humanos tienen una disposición en busca de la auto-realización, pero también tiene una propensión en dirección a la regresión, al miedo de crecer. Para el autor "estas tendencias opuestas siempre entran en equilibrio y se relacionan unas con otras de forma dialéctica”. Postula que en ultima instancia, la gerencia aclarada es un medio para desarrollar la espiritualidad, la conciencia cósmica, en términos de intensa preocupación con las cuestiones del hombre, con la ética, con la naturaleza, en fin, con el futuro de la humanidad ${ }^{(1)}$.

Considera, también que la persona sea suficientemente corajuda para envolverse en el proceso aclarado, lo que significa que a pesar de los recelos que pueda sentir, siga adelante en la conquista de sus realizaciones.

\section{EL TRABAJO GERENCIAL DEL ENFERMERO}

Gerencia y liderazgo han representado un desafío a ser enfrentado por los servicios de prestación de la atención a la salud en nuestro medio, específicamente por los servicios de enfermería. El desafío se establece porque las medidas adoptadas hasta entonces, en sus practicas organizacionales, han violado la autonomía de los enfermeros, subyugándolos a comandos y ritmos insensibles a su individualidad, favoreciendo la alienación de sí mismo, de sus prójimos y de la naturaleza. Todo se convierte en desaliento, como si los enfermeros y sus colaboradores no tuviesen potencial para ser explorado, como si no pudiesen despertar, como si fuese imposible conducir y ser conducido sin la rigidez y la precisión de la sabiduría convencional de la administración. Lo peor es que parece que ese escenario se hace efectivo sino con el consentimiento, por lo menos con la indiferencia del enfermero.

Nuestras organizaciones de salud aún no introyectaron en su cotidiano la debida valorización del 
hombre trabajador y de sus ansias más fundamentales. De ésta forma, de modo general, la actuación del enfermero gerente a estado mucho más allá de lo que el realmente puede ofrecer - si las condiciones y el contexto del trabajo sufren las modificaciones necesarias, recubiertas de un nuevo significado de gerencia y liderazgo y sobretodo, si el enfermero se concientiza y cree verdaderamente que su competencia humana y técnica, unida al conocimiento gerencial, es condición fundamental para el cambio requerido y para la diferencia esperada.

En la opinión de las autoras, la Gerencia Aclarada se constituye en un referencial de fuerte impacto, capaz de sensibilizar y posibilitar la reflexión del enfermero sobre la gerencia de las acciones de enfermería centradas en la atención y en el cuidado al cliente.

El campo de la enfermería es altamente propicio para la implementación de las ideas de Maslow ${ }^{(1)}$, dado que su objeto de trabajo es el ser humano en sus distintas faces. Es por lo tanto, un trabajo con significado en términos de procesos, objetivos y metas. En este sentido, al enfermero que escogió ser enfermero le gusta y aprecia lo que hace, busca cada vez hacerlo mejor. Su trabajo se identifica con su yo, integra su persona y siendo así, él estará encuadrado en el proceso de auto-realización. En otros términos, él estará realizando lo que desea y está apto para realizar, desarrollando sus capacidades y talentos, concretizando su potencial y obteniendo paz.

En el proceso de auto-realización, incentivado por la gerencia aclarada, el enfermero se siente con libertad para implementar sus ideas, experimentar e innovar, asumir las consecuencias de las decisiones que toma, escoger sus colaboradores, sus compañeros. Tiene la comprensión de que perseverancia, enfrentamiento y tolerancia a las dificultades o frustraciones integran su maduración, su disposición de conseguir, obtener resultados y su creencia en el significado de su trabajo.

En el contexto actual del trabajo gerencial del enfermero, las relaciones sociales estigmatizadas por manipulaciones, incomprensiones, conflictos, errores, descuidos, han traído consecuencias nocivas a las necesidades de estima y de autoestima de este profesional que no se está sintiendo importante, respetado, no está sintiendo la debida valorización que su trabajo le podría proporcionar en caso de que estuviese comprometido e involucrado en circunstancias diferentes. Sin duda, esto tiene repercusión altamente negativa y contagia su personal colaborador.
El rescate de la autoestima y de la dignidad del enfermero se dará a través de una actitud determinada, activa y persistente frente a su trabajo gerencial - una vez más insistimos que la alternativa fundamentada en las presunciones de la gerencia aclarada (que en la visión de varios estudiosos presenta consideraciones relevantes en relación con la naturaleza humana y la naturaleza del trabajo) es convincente y pertinente a ese tiempo de crisis de ese profesional.

La diligencia esencial de cada ser humano es mejorar a sí mismo ${ }^{(1)}$. En esta tarea el enfermero no tiene competidor y al asumirla se estará apropiando de sus potenciales humanos posibilitándoles su desarrollo según sus creencias y valores personales y profesionales, sin dejarse humillar por cualquier manifestación que reduzca, encuadre o desvalorice al hombre.

Como consecuencia del empeño en la tarea de mejorar a sí mismo, el contexto del trabajo también se torna superior. En las relaciones y en las acciones el enfermero expresa su singularidad y considera también la individualidad de cada colaborador, teniendo siempre en perspectiva que las personas pueden ser actualizadas. Siendo así, centraliza y enfatiza la persona, sus sentimientos, sus talentos, sus competencias y sus debilidades, favoreciendo el desarrollo de la capacidad de empatía y de la estima.

En la gerencia aclarada no hay espacio para la jerarquía de dominancia-subordinación caracterizada por el autoritarismo. Lejos de eso, compañerismo, metas y responsabilidades compartidas y hasta afectividad entre el personal de enfermería, se derivan de la relación interpersonal, de la cooperación, de la sinergia, del buen desempeño en equipo y del sentimiento saludable de pertenencia. En este contexto, existe la identificación de los comprometidos con los objetivos del servicio, es decir, las personas llegan a un consenso y tienen objetivos comunes, independiente de sus posiciones en la organización.

Sabemos que la vida de trabajo en una organización de enfermería requiere mucha información. De ésta forma, las personas deben ser informadas, mientras que sea posible, de todos los acontecimientos y verdades relevantes a la situación.

Reacciones adversas, resentimientos e irritaciones son esperados en nombre de una buena causa o razón. La libertad de manifestar hostilidad, por parte de cualquier persona del equipo de enfermería, incrementa la honestidad y contribuye para mejorar la situación. El enfermero debe 
demostrar actitud receptiva frente a las manifestaciones de discordancias relacionadas con su postura, acción y además de actuar con honestidad, procurar siempre comprender y transmitir la importancia de la diversidad.

En líneas generales, las autoras abordaron la contribución que la Gerencia Aclarada, rodeada de principios benéficos y benévolos, puede ofrecer al enfermero en el ejercicio de su trabajo gerencial y de liderazgo, específicamente en puntos relevantes como crecimiento profesional, autorealización, desarrollo personal y florecimiento humano. Tales aspectos, conforme fueron presentados, buscan alcanzar la plenitud del hombre, una vez que se vinculan a la dimensión mística.
Por lo tanto, encuentran en la Gerencia Aclarada una base para el desarrollo de la espiritualidad.

\section{CONCLUSIÓN}

El significado del trabajo del enfermero puede ser resaltado con la implementación de los presupuestos del proceso gerencial aclarado. Nuestra expectativa es que, después de reflexiones, al enfermero no le faltarán coraje y determinación para envolverse en ese proceso y de ésta forma, recuperar la autoestima y el entusiasmo tan distantes de ese profesional en este momento.

\section{REFERENCIAS BIBLIOGRÁFICAS}

1. Maslow AH. Maslow no gerenciamento. Rio de Janeiro: Qualitymark Ed.; 2000.

2. Fromm E. A arte de amar. São Paulo (SP): Martins Fontes; 2000.

3. Hesselbein F. O sonho que se coloca à nossa frente. In: Hesselbein F, Goldsmith M, Beckhard R, Schubert RF, editores. A comunidade do futuro: idéias para uma nova comunidade. São Paulo (SP): Futura; 1998.

4. Pinchot G. Desenvolvendo a comunidade no local de trabalho. In: Hesselbein F, Goldsmith M, Beckhard R, Schubert $\mathrm{RF}$, editores. A comunidade do futuro: idéias para uma nova comunidade. São Paulo (SP): Futura; 1998.

5. Drucker PF. Introdução: rumo à nova organização. In: Hesselben F, Goldsmith M, Beckhard R, editores. A organização do futuro: como preparar hoje as empresas de amanhã. São Paulo (SP): Futura; 1997. 